\title{
Antiplasmodial and antileishmanial activities of compounds from Piper tuberculatum Jacq fruits
}

\author{
Flávio Augusto de Souza Oliveira ${ }^{[1]}$, Guilherme Matos Passarini ${ }^{[2]}$, \\ Daniel Sol Sol de Medeiros ${ }^{[2]}$, Ana Paula de Azevedo Santos ${ }^{[2]}$, Saara Neri Fialho ${ }^{[2]}$, \\ Aurileya de Jesus Gouveia ${ }^{[2]}$, Marcinete Latorre ${ }^{[2]}$, Elci Marlei Freitag ${ }^{[2]}$, \\ Patrícia Soares de Maria de Medeiros ${ }^{[3]}$, Carolina Bioni Garcia Teles ${ }^{[2],[4],[5]}$ \\ and Valdir Alves Facundo ${ }^{[6]}$
}

\author{
[1]. Departamento de Biomedicina, Faculdade de Educação e Cultura de Vilhena, Vilhena, RO, Brasil. \\ [2]. Plataforma de Bioensaios em Malária e Leishmaniose/Fundação Oswaldo Cruz - Rondônia, Porto Velho, RO, Brasil. \\ [3]. Departamento de Ciências Biológicas, Fundação Universidade Federal de Rondônia, Porto Velho, RO, Brasil. \\ [4]. Departamento de Ciências Biológicas, Centro Universitário São Lucas, Porto Velho, RO, Brasil. \\ [5]. Instituto Nacional de Epidemiologia na Amazônia Ocidental, Porto Velho, RO, Brasil. \\ [6]. Departamento de Química, Fundação Universidade Federal de Rondônia, Porto Velho, RO, Brasil.
}

\begin{abstract}
Introduction: This study assessed the activity of compounds from Piper tuberculatum against Plasmodium falciparum and Leishmania guyanensis. Methods: The effects of compounds from P. tuberculatum fruits on P. falciparum and L. guyanensis promastigote growth in vitro were determined. Hemolytic action and cytotoxicity in HepG2 and J774 cells were measured. Results: Three compounds showed strong antiplasmodial activity and one compound showed strong antileishmanial activity. Two compounds were non-toxic to HepG2 cells and all were toxic to J774 cells. The compounds showed no hemolytic activity. Conclusions: The tested compounds from P. tuberculatum exhibited antiparasitic and cytotoxic effects.
\end{abstract}

Keywords: Malaria. Leishmaniasis. Piper. Bioactivity.

Neglected tropical diseases disproportionately affect poor populations throughout the world, resulting in a severe burden within endemic regions. Among these diseases, malaria and leishmaniasis are protozoal infections with the highest number of cases and deaths ${ }^{1}$; therefore, studies involving new methods of interventions for these diseases are highly relevant to public health. Piper tuberculatum, an Amazonian medicinal plant, is a species from which many amide alkaloids have been isolated and it is used as a traditional medicine for the treatment of gastric disorders ${ }^{2}$. The species has a broad spectrum of biological activities, including insecticidal ${ }^{3}$, antileishmanial ${ }^{4}$, and trypanocidal actions ${ }^{5}$. Owing to its pharmacological potential, this study aimed to evaluate the antiplasmodial and antileishmanial potential of extracts, fractions, subfractions, and an isolated compound from $P$. tuberculatum against Plasmodium falciparum and Leishmania guyanensis.

Piper tuberculatum fruits $(1.3 \mathrm{~kg})$ were collected from a central area in Porto Velho City, State of Rondônia, Brazil, and the plant material was subsequently identified at the herbarium

Corresponding author: Msc Guilherme Matos Passarini

e-mail: guilhermepassarini@hotmail.com

Received 26 July 2017

Accepted 17 November 2017 of Instituto Nacional de Pesquisa da Amazônia (INPA), where an exsiccata was deposited (number 211724). The crude extract of P. tuberculatum fruits (40g), named PTFCE (Piper tuberculatum fruits crude extract), was obtained by percolation with ethanol (99\%) for 3 days, followed by solvent evaporation. Some of the dried extract $(38.2 \mathrm{~g})$ was subjected to silica gel column chromatography and eluted with hexane, chloroform, ethyl acetate, and methanol, yielding the PTFHF (Piper tuberculatum fruits - hexane fraction), PTFCF (Piper tuberculatum fruits - chloroform fraction), PTFEAF (Piper tuberculatum fruits ethyl acetate fraction extract), and PTFMF (Piper tuberculatum fruits - methanol fraction) fractions, respectively ${ }^{6}$. PTFHF was then fractioned and eluted in a hexane/chloroform gradient of increasing polarity, yielding the fractions HF-1 (hexane fraction 1), HF-2 (hexane fraction 2), HF-3 (hexane fraction 3), HF-4 (hexane fraction 4), HF-5 (hexane fraction 5), HF-6 (hexane fraction 6), and HF-7 (hexane fraction 7). HF-6 presented a solid white precipitate that was dissolved in chloroform and recrystallized. The $1 \mathrm{D}$ and $2 \mathrm{D}^{1} \mathrm{H}-\mathrm{NMR}$ and ${ }^{13} \mathrm{C}-\mathrm{NMR}$ data and mass spectrum of the purified compound matched that of pellitorine, a molecule previously isolated from fruits of P. tuberculatum (Figure 1).

Human erythrocytes were used for the P. falciparum W2 (cloroquine-resistant Indochine strain) strain culture. The 


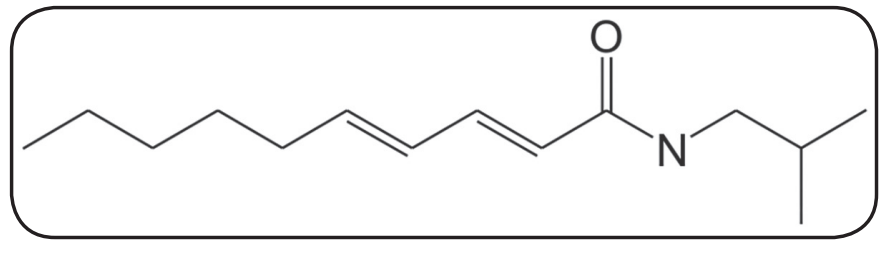

FIGURE 1: Pellitorine structure.

parasite was cultured with complete Roswell Park Memorial Institute-1640 (RPMI-1640) medium (HEPES, 22.8mM; glucose $11.1 \mathrm{mM}$; hypoxanthine, $0.36 \mathrm{mM}\left(50 \mu \mathrm{g} . \mathrm{mL}^{-1}\right)$; $\mathrm{NaHCO}_{3}, 23.8 \mathrm{mM}$ ), supplemented with $1 \%$ albumax and $5 \%$ hematocrit. The parasites were maintained in an incubator at $37^{\circ} \mathrm{C}$ under an atmosphere of $5 \% \mathrm{O}_{2}, 5 \% \mathrm{CO}_{2}$, and balanced $\mathrm{N}_{2}$. The culture was subsequently synchronized with sorbitol $(0.5 \%)^{7}$ to maintain only ring forms and the hematocrit was adjusted to $1.5 \%$ for the tests, in which the parasitemia was $0.05 \%$. The culture was then incubated for $48 \mathrm{~h}$ with the $P$. falciparum culture. Triplicate experiments with concentrations between 1.56 and $100 \mu \mathrm{g} / \mathrm{mL}$ were conducted. The negative control consisted of infected erythrocytes without treatment and the positive control consisted of serial dilutions of artemisinin from 50 to $1.56 \mathrm{ng} / \mathrm{mL}$. For all biological assays, $0.5 \%$ dimethyl sulfoxide [(DMSO) Sigma-Aldrich)] was used as the negative control. To assess the effect of the test compounds on $P$. falciparum growth, an anti-HRPII (histidine-rich protein) assay was performed ${ }^{8}$. Two $96-$ well plates were prepared: a test plate, containing the parasites and the test compounds, and another plate precoated with monoclonal antibodies against the P. falciparum HRPII antigen. To sensitize the plates, $100 \mu \mathrm{L}$ of primary antibody (MPFM-Plasmodium falciparum antibody$\left.55 \mathrm{AICLLAB}{ }^{\circledR}, \mathrm{EUA}\right)$ at $1.0 \mu \mathrm{g} / \mathrm{mL}$ was added to each well. The test plates were incubated for $24 \mathrm{~h}$; subsequently, the background (control culture) was withdrawn and frozen at $-20^{\circ} \mathrm{C}$ for later use. The plate was incubated again and subjected to two freezethaw cycles at $-80^{\circ} \mathrm{C}$ to lyse the erythrocytes. After the plates were incubated and washed, $100 \mu \mathrm{L}$ of the secondary antibody (MPFG55P ICLLAB®, EUA; 1:5,000 dilution) was added to each well. The plate was incubated further, washed again three times, at which point $100 \mu \mathrm{L}$ 3,3',5,5'-tetramethylbenzidine (TMB) was added to each well. The absorbance at $450 \mathrm{~nm}$ was measured by using a microplate spectrophotometer (BIOCHRON Model: Expert plus).

The $\mathrm{IC}_{50}$, the concentration at which a compound kills $50 \%$ of the parasite population, was obtained by nonlinear curve fitting of the serial concentrations computed by Origin software (OriginLab Corporation, Northampton, MA, USA). Compounds with an $\mathrm{IC}_{50}$ below $10 \mu \mathrm{g} / \mathrm{mL}$ were considered active; values of $10-25 \mu \mathrm{g} / \mathrm{mL}$ were considered partially active and values of $\geq 25 \mu \mathrm{g} / \mathrm{mL}$ were considered inactive. The percentage of parasite growth inhibition for each concentration was calculated from the following formula:

Activity $(\%)=100-[($ test compounds - positive control $) /$ (negative control - positive control) $] \times 100$
Leishmania guyanensis promastigotes (IOCL 565) were obtained from the Leishmania Collection of the Oswaldo Cruz Institute - CLIOC/FIOCRUZ and cultured in vitro at $24^{\circ} \mathrm{C}$ in RPMI 1640 (Sigma) supplemented with 10\% inactivated fetal bovine serum [(FBS); Gibco/Invitrogen], 2mM L-glutamine, 20mM HEPES (N-2-hydroxyethylpiperazine-N'-22, ethanesulfonic acid), and $40 \mu \mathrm{g} / \mathrm{mL}$ gentamicin (Sigma). The promastigotes $\left(1 \times 10^{6}\right.$ parasites $\left./ 180 \mu \mathrm{L}\right)$ were then introduced into each well of a 96 -well plate containing the test compounds from P. tuberculatum $(1.56-100 \mu \mathrm{g} / \mathrm{mL})$. The negative and positive controls were DMSO $(0.5 \%)$ and pentamidine, respectively. The plates containing the parasites and test compounds were incubated at $24^{\circ} \mathrm{C}$ for $72 \mathrm{~h}$. After incubation, $10 \mu \mathrm{L} /$ well MTT (3-(4,5-dimethylthiazol-2-yl)-2,5-diphenyltetrazolium bromide) was added and the plate was incubated for $4 \mathrm{~h}$. Subsequently, the plates containing the cultures were centrifuged for 10 min and the supernatant was discarded. DMSO $(100 \mu \mathrm{L} /$ well) was then added and the plate was incubated for $1 \mathrm{~h}$ at $24^{\circ} \mathrm{C}^{9}$. The experiments were performed twice, with all samples tested in triplicate in each experiment, and a mean value was calculated. The absorbance at 570nm was measured by using a spectrophotometer. The calculated $\mathrm{IC}_{50}$ values were classified as previously described.

For the cytotoxicity analysis, HepG2 and J774 cells were cultured as recommended by Calvo-Calle et al. ${ }^{10}$ and the MTT assay was used to assess cell viability ${ }^{11}$. The cells were seeded at $2 \times 10^{4} /$ well and after treatment $(24 \mathrm{~h}$ for HepG2 and $72 \mathrm{~h}$ for J774) with the test compounds $(4.68-100 \mu \mathrm{g} / \mathrm{mL}), 10 \mu \mathrm{L}$ MTT was added to each well. The plates were incubated with MTT for $4 \mathrm{~h}$ at $37^{\circ} \mathrm{C}$. After incubation, the supernatant was aspirated and $100 \mu \mathrm{L}$ DMSO was added to each well. The optical density at $540 \mathrm{~nm}$ was then determined. The negative control comprised cells in the absence of any test compound and the positive control comprised cells treated with $1 \%$ DMSO. The tests were performed twice, with samples in triplicate in each experiment, and subsequently, the $\mathrm{CC}_{50}(50 \%$ cytotoxicity concentration) was obtained by non-linear curve fitting of the serial concentration data of the tested compounds computed using Origin. The cytotoxic status of the compounds was determined based on their selectivity index (SI), which was calculated from the ratio of the $\mathrm{CC}_{50}$ and $\mathrm{IC}_{50}\left(\mathrm{IS}=\mathrm{CC}_{50} / \mathrm{IC}_{50}\right)$. Compounds with an SI of $<10$ were considered non-selective/ toxic; compounds with an SI of $\geq 10$ were considered selective/ non-toxic. The cytotoxic effect of each compound concentration was generated by the formula:

Cytotoxicity $\%=100-[($ test compounds - positive control $) /$ (negative control - positive control) $] \times 100$

The hemolysis assay was performed according to the method of Wang et al. ${ }^{12}$; the test compounds were serially diluted from 100 to $1.56 \mu \mathrm{g} / \mathrm{mL}$ with $0.05 \%$ DMSO.

The crude extract of $P$. tuberculatum was not active against $P$. falciparum (Table 1). Of all fractions, only PTFCF $\left(\mathrm{IC}_{50}=9.81 \mu \mathrm{g} / \mathrm{mL}\right)$ was considered active. The assessment of the cytotoxicity of the compounds by the MTT colorimetric method revealed that PTFCE was toxic ( $\mathrm{SI} \leq 0.4)$. The previously reported isolation of $\beta$-sitosterol, stigmasterol, 
TABLE 1: Biological activity of $P$. tuberculatum compounds against the W2 strain of $P$. falciparum and cytotoxic evaluation in the HepG2 cell line.

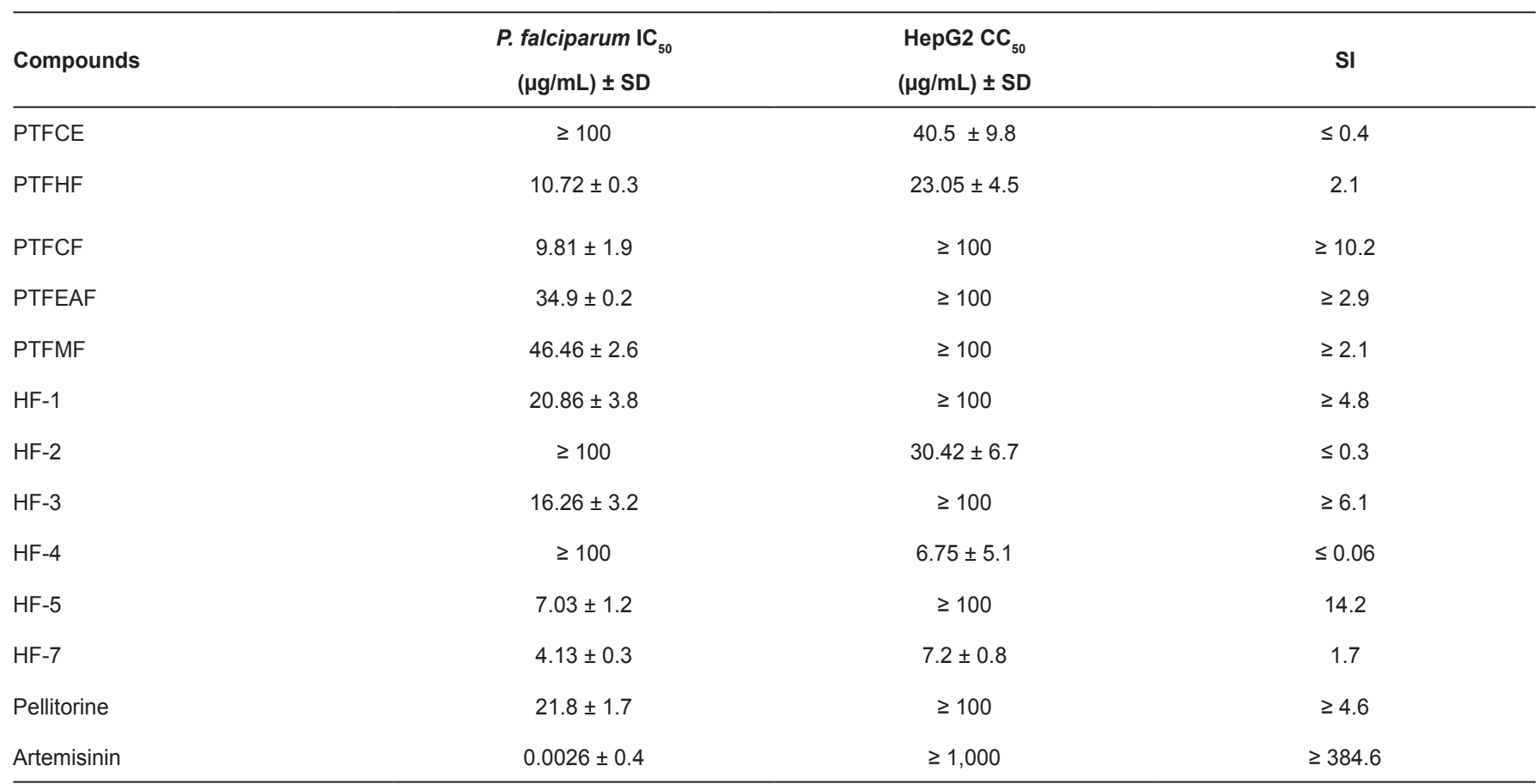

P. tuberculatum: Piper tuberculatum; $\boldsymbol{P}$. falciparum: Plasmodium falciparum; W2: cloroquine-resistant Indochina clone; HepG2: liver hepatocellular carcinoma; IC I $_{50}$ inhibition of $50 \%$ of parasite growth; $\mathbf{C C}_{50}: 50 \%$ cytotoxicity concentration; SD: standard deviation; DMSO: dimethyl sulfoxide; CC $_{50}: 50 \%$ cytotoxic concentration in mammalian cells. SI: selectivity index $\left(\mathrm{CC}_{50} / \mathrm{IC}_{50}\right)$. The IC $\mathrm{C}_{50}$ value of the positive control, artemisinin, was $2.6 \mathrm{ng} / \mathrm{mL}$. The solvent (0.5\% DMSO) was not toxic to HepG2 cells nor to $P$. falciparum (data not shown). PTFCE: crude extract of $P$. tuberculatum fruits; PTFHF: hexane fraction of $P$. tuberculatum fruits; PTFCF: chloroform fraction of $P$. tuberculatum fruits; PTFEAF: ethyl acetate fraction of $P$. tuberculatum fruits; PTFMF: methanol fraction of $P$. tuberculatum fruits; HF-1: hexane fraction 1; HF-2: hexane fraction 2; HF-3: hexane fraction 3; HF-4: hexane fraction 4; HF-5: hexane fraction 5; HF-7: hexane fraction 7.

3-(3,4,5-trimethoxyphenyl) propanoic acid, piplartine, and dihydropiplartine from the chloroform fraction of $P$. tuberculatum (6) suggested that the activity of PTFCF may be attributable to one of these compounds. The analysis of the cytotoxicity also indicated that PTFCF was the only fraction considered non-toxic to HepG2 cells ( $\mathrm{SI} \geq 10.2$ ).

Of the hexane subfractions, only HF-5 $\left(\mathrm{IC}_{50}=7.03 \mu \mathrm{g} / \mathrm{mL}\right)$ and HF-7 $\left(\mathrm{IC}_{50}=4.13 \mu \mathrm{g} / \mathrm{mL}\right)$ were considered active; HF-7 had the highest antiplasmodial activity of the test compounds $\left(\mathrm{IC}_{50}\right.$ $=4.13 \mu \mathrm{g} / \mathrm{mL}$ ). HF-2, HF-4, and HF-7 were toxic to HepG2 cells, with SI values of $\leq 0.3, \leq 0.06$, and 1.7 , respectively, and were therefore non-selective for $P$. falciparum. HF-5 was the only non-toxic subfraction and the most selective compound against $P$. falciparum $(\mathrm{SI}=14.2)$.

The compound pellitorine (Figure 1) was partially active against $P$. falciparum $\left(\mathrm{IC}_{50}=21.8 \mu \mathrm{g} / \mathrm{mL}\right)$, with $\mathrm{CC}_{50} \geq 100 \mu \mathrm{g} /$ $\mathrm{mL}$ for HepG2; it may either be selective or not against this parasite, as its exact $\mathrm{SI}$ is unknown (SI $\geq 4.6)$. Weenen et al. ${ }^{13}$ reported an $\mathrm{IC}_{50}$ of $20 \mu \mathrm{g} / \mathrm{mL}$ for pellitorine on the $\mathrm{K} 10$ strain of $P$. falciparum; however, as cytotoxicity assays were not conducted, the authors could not assess the selectivity of this compound. Similar actions in the W2 (chloroquine-resistant) and K10 (mefloquine-resistant) strains suggested a common mode of action in both strains. Heme formation, protein synthesis, and PfDHFR ( $P$. falciparum dihydrofolate reductase) activity inhibition ${ }^{14}$ are possible molecular targets for pellitorine, as these are common mechanisms of action of antimalarial compounds.

Hemolytic assays were also performed to investigate whether the compounds inhibited $P$. falciparum growth via erythrocyte lysis. However, it was found that none of the compounds resulted any degree of hemolysis in human erythrocytes (data not shown).

To the best of our knowledge, this is the first study to report the anti-L. guyanensis activity of compounds from $P$. tuberculatum. The crude extract was not active against this parasite (Table 2) and was considered toxic to the J774 cell line ( $\mathrm{SI} \leq 1.58)$; the only partially active fraction was PTFCF $\left(\mathrm{IC}_{50}=19.98 \mu \mathrm{g} / \mathrm{mL}\right)$, which was also toxic to $\mathrm{J774}$ $(\mathrm{SI}=0.21)$. Ferreira et al. (4) described the isolation of 3-(3,4,5-trimethoxyphenyl) propanoic acid, obtained from the hexane/ethyl acetate $(35: 65)$ extraction of the fruits of $P$. tuberculatum, and reported an $\mathrm{IC}_{50}$ of $145 \mu \mathrm{g} / \mathrm{mL}$ for this molecule against $L$. amazonensis promatigotes. In the present study, the ethyl acetate fraction was unable to inhibit the growth of L. guyanensis, probably owing to the antagonism of other compounds present in the fraction or to the absence or low concentration of 3-(3,4,5-trimethoxyphenyl) propanoic acid. A more detailed analysis of the phytochemical profile of this fraction is needed to confirm the content of this compound and the presence of other substances with antiparasitic action 
TABLE 2: Biological activity of $P$. tuberculatum compounds against $L$. guyanensis and cytotoxicity evaluation in the J774 cell line.

\begin{tabular}{|c|c|c|c|}
\hline Compounds & L. guyanensis $\mathrm{IC}_{50}(\mu \mathrm{g} / \mathrm{mL}) \pm \mathrm{SD}$ & $\begin{array}{c}\mathrm{J} 774 \mathrm{CC}_{50} \\
(\mu \mathrm{g} / \mathrm{mL}) \pm \mathrm{S} D\end{array}$ & SI \\
\hline PTFCE & $\geq 100$ & $63.2 \pm 5.2$ & $\leq 1.58$ \\
\hline PTFHF & $93.89 \pm 8.4$ & $\geq 100$ & $\geq 1.06$ \\
\hline PTFCF & $19.98 \pm 1.3$ & $4.2 \pm 1.3$ & 0.21 \\
\hline PTFEAF & $\geq 100$ & $48.94 \pm 0.9$ & $\leq 0.48$ \\
\hline PTFMF & $\geq 100$ & $\geq 100$ & --- \\
\hline $\mathrm{HF}-1$ & $\geq 100$ & $\geq 100$ & -- \\
\hline $\mathrm{HF}-2$ & $14.4 \pm 0.7$ & $75.77 \pm 0.1$ & 5.26 \\
\hline $\mathrm{HF}-3$ & $\geq 100$ & $\geq 100$ & --- \\
\hline $\mathrm{HF}-4$ & $10.15 \pm 1.9$ & $3.8 \pm 0.9$ & 0.37 \\
\hline HF-5 & $\geq 100$ & $\geq 100$ & -- \\
\hline $\mathrm{HF}-7$ & $2.75 \pm 0.5$ & $1.6 \pm 0.07$ & 0.58 \\
\hline Pellitorin & $26.84 \pm 9.4$ & $67.8 \pm 9.3$ & 2.52 \\
\hline Pentamidine & $0.87 \pm 0.8$ & $6.13 \pm 0.9$ & 7.04 \\
\hline
\end{tabular}

P. tuberculatum: Piper tuberculatum; L. guyanensis: Leishmania guyanensis; $\mathbf{I C}_{50}$ : inhibition of $50 \%$ of parasite growth; $\mathbf{C C}_{50}: 50 \%$ cytotoxicity concentration; SD: standard deviation; SI: selectivity index $\left(\mathrm{CC}_{50} / \mathrm{IC}_{50}\right)$; ---: selectivity index not calculated; $\mathrm{CC}_{50}: 50 \%$ cytotoxic concentration in mammalian cells; DMSO: dimethyl sulfoxide; The IC value of the positive control, pentamidine, was $0.87 \mu \mathrm{g} / \mathrm{mL}$. The solvent DMSO $(0.5 \%)$ showed neither antileishmanial activity nor toxicity towards J774 (data not shown). PTFCE: crude extract of $P$. tuberculatum fruits; PTFHF: hexane fraction of $P$. tuberculatum fruits; PTFCF: chloroform fraction of $P$. tuberculatum fruits; PTFEAF: ethyl acetate fraction of $P$. tuberculatum fruits; PTFMF: methanol fraction of $P$. tuberculatum fruits; HF-1: hexane fraction 1; HF-2: hexane fraction 2; HF-3: hexane fraction 3; HF-4: hexane fraction 4; HF-5: hexane fraction 5; HF-7: hexane fraction 7.

observed in this study. Of the subfractions, only HF-7 was considered active against the parasite $\left(\mathrm{IC}_{50}=2.75 \mu \mathrm{g} / \mathrm{mL}\right)$, although its effect on $\mathrm{J} 774$ cell viability $\left(\mathrm{CC}_{50}=1.6 \mu \mathrm{g} / \mathrm{mL}\right)$ led to its characterization as a toxic compound $(\mathrm{SI}=0.58)$.

The purified compound pellitorine was considered inactive against $L$. guyanensis $\left(\mathrm{IC}_{50}=26.84 \mu \mathrm{g} / \mathrm{mL}\right)$, although the SI (2.52) suggested that the molecule was non-selective for L. guyanensis and the $\mathrm{J} 774$ cell line; however, the potential of pellitorine against amastigote forms of L. guyanensis should be determined, as it is the parasitic form normally found in this vertebrate organism and it is possible that the low selectivity of this molecule observed in this study for both P. falciparum and L. guyanensis could be improved with structural modifications of the molecule by using a semi-synthetic approach.

A remarkable fact observed in the present experiments was the greater susceptibility of $P$. falciparum than $L$. guyanensis to the tested compounds. This phenomenon may result from genetic plasticity, a constitutive feature of the Leishmania genus. It has been demonstrated that Leishmania spp. vary the number of chromosomal copies with changing environmental conditions, a feature that possibly plays an important role in drug resistance ${ }^{15}$.

In conclusion, the subfraction HF-7 was the most active against the evaluated parasites, and HF- 5 was the most selective for P. falciparum. Although the compounds exhibited activity against the parasites and were not hemolytic, there was some degree of toxicity in mammalian cell lines. This study has expanded our knowledge of the antiparasitic potential of $P$. tuberculatum and has highlighted the importance of identification of the individual substances present in the subfractions that are responsible for the observed antiprotozoal and cytotoxic effects.

\section{Acknowledgements}

The authors express their gratitude to Amy Grabner for the English review of the present manuscript and Fundação Oswaldo Cruz (FIOCRUZ)-RO and Universidade Federal de Rondônia (UNIR) for the opportunity to conduct this research.

\section{Conflict of interest}

The authors declare that there is no conflict of interest.

\section{Financial support}

Instituto Nacional de Epidemiologia na Amazônia Ocidental, Porto Velho, Rondônia, Brasil.

\section{REFERENCES}

1. Bhutta ZA, Sommerfeld J, Lassi ZS, Salam RA, Das JK. Global burden, distribution, and interventions for infectious diseases of poverty. Infect Dis Poverty. 2014;3(1):21-7.

2. Burci LM, Pereira IT, Silva LM, Rodrigues RV, Facundo VA, Militão JSLT, et al. Antiulcer and gastric antisecretory effects of 
dichloromethane fraction and piplartine obtained from fruits of Piper tuberculatum Jacq. in rats. J Ethnopharmacol. 2013;148(1):165-74.

3. Scott IM, Jensen H, Nicol R, Lesage L, Bradbury R, Sánchesvindas LP, et al. Efficacy of Piper (Piperaceae) extracts for control of common home and garden insect pest. J Econ Entomol. 2004;97(4):1390-403.

4. Ferreira MGPR, Kayano AM, Silva-Jardim I, Silva TO, Zuliani JP, Facundo VA, et al. Antileishmanial activity of 3-(3, 4, 5-trimethoxyphenyl) propanoic acid purified from Amazonian Piper tuberculatum Jacq., Piperaceae, fruits. Rev Bras Farmacogn. 2010;20(6):103-6.

5. Regasini LO, Cotinguiba F, Passerini GD, Bolzani VS, Cicarelli RMB, Kato MJ, et al. Trypanocidal activity of Piper arboreum and Piper tuberculatum (Piperaceae). Rev Bras Farmacogn. 2009;19(1B):199-203.

6. Facundo VA, Polli AR, Rodrigues RV, Militão JSLT, Stabelli RG, Cardoso CT. Constituintes químicos fixos e voláteis dos talos e frutos de Piper tuberculatum Jacq. e das raízes de P. hispidum H. B. K. Acta Amazon. 2008;38(4):733-42.

7. Lambros C, Vanderberg J. Synchronization of Plasmodium falciparum erythrocytic stages in culture. J Parasitol. 1979;65(3):418-20.

8. Noedl H, Wernsdorfer WH, Miller RS, Wongsrichanalai C. Histidine-rich protein II: a novel approach to malaria drug sensitivity testing. Antimicrob Agents Chemother. 2002;46(6):1658-64.
9. Pal D, Bhattacharya S, Baidya P, Dey BK, Pandey JN, Moulisha B. Antileishmanial activity of Polyalthia leaf extract on the in vitro growth of Leihmaniose donovani promastigotes. Global J Pharmacol. 2011;5(2):97-100.

10. Calvo-Calle JM, Moreno A, Eling WMC, Nardin EH. In vitro development of infectious liver stages of $P$. yoelii and $P$. berghei malaria in human cell lines. Exp Parasitol. 1994;79(3):362-73.

11. Mosmann T. Rapid colorimetric assay for cellular growth and survival: application to proliferation and cytotoxicity assays. J Immunol Methods. 1983;65(1):55-63.

12. Wang C, Qin X, Huang B, He F, Zeng C. Hemolysis of human erythrocytes induced by melamine-cyanurate complex. Biochem Biophys Res Commun. 2010;402(4):773-7.

13. Weenen H, Nkuya MHH, Bray DH, Mwasumbi LB, Kinabo LS, Kilimali VAEB, et al. Antimalarial compounds containing an $\alpha$, $\beta$-unsaturated carbonyl moiety from Tanzanian medicial plants. Planta Med. 1990;56(4):371-3.

14. Burrows JN, Chibale K, Wells TNC. The state of the art in antimalarial drug discovery and development. Curr Top Med Chem. 2011;11(10):1226-54.

15. Mannaert A, Downing T, Imamura H, Dujardin J. Adaptive mechanisms in pathogens: universal aneuploidy in Leishmania. Trends Parasitol. 2012;28(9):370-6. 